\title{
MODEL INFLASI DI INDONESIA DENGAN MENGGUNAKAN ARIMA
}

\author{
LATHIFAH YULYANISA, DODI DEVIANTO, MAIYASTRI \\ Program Studi Matematika, \\ Fakultas Matematika dan Ilmu Pengetahuan Alam, Universitas Andalas, \\ Kampus UNAND Limau Manis Padang, Indonesia, \\ lathifahyulyanisa@ymail.com
}

\begin{abstract}
Abstrak. Kenaikan harga barang dan jasa dimana barang dan jasa merupakan kebutuhan pokok masyarakat disebut dengan inflasi. Salah satu metode yang dapat digunakan untuk menduga nilai inflasi adalah dengan menggunakan ARIMA. Model ARIMA terdiri dari model Autoregreesive (AR) dan model Moving Average (MA). Dimana model ini adalah salah satu pemodelan untuk data deret waktu. metode ini diaplikasikan pada data nilai inflasi periode 2007 sampai 2014 dengan data yang bersifat bulanan. Hasil yang diperoleh adalah model ARIMA $(1,1,12)$ sebagai model terbaik. Sehingga diperoleh ramalan nilai inflasi untuk periode selanjutnya. Hasil tersebut dibandingkan dengan data aktual dimana data yang diperoleh tidak jauh berbeda dengan data aktual.
\end{abstract}

Kata Kunci: Metode ARIMA, Inflasi, Forecasting

\section{Pendahuluan}

Inflasi merupakan kenaikan harga barang dan jasa secara umum dimana barang dan jasa merupakan kebutuhan pokok masyarakat atau turunnya daya jual mata uang suatu negara. Nilai inflasi bisa saja meningkat ataupun menurun pada waktu tertentu. Oleh karena itu dibutuhkan pemodelan inflasi yang tepat agar peramalan bisa mendekati inflasi yang sebenarnya. Untuk menentukan metode peramalan yang sesuai dengan data, maka perlu diketahui pola data tersebut.

Setelah diketahui pola data dan diperoleh model yang sesuai, maka peramalan dapat dilakukan. Dalam menentukan peramalan (forecasting) atau prediksi suatu inflasi, diperlukan metode, model ataupun pendekatan yang teruji ketepatannya. Semakin teruji model yang diperoleh semakin diminati model tersebut untuk digunakan.

Dalam paper ini yang akan dibahas adalah Model ARIMA (Autoregressive Integrated Moving Average) yang merupakan model peramalan yang menggunakan data masa lalu yang digunakan untuk mengamati suatu kejadian pada data tersebut. Model ARIMA diaplikasikan pada nilai inflasi di Indonesia yang diterbitkan oleh Bank Indonesia pada tahun 2007 hingga 2014.

\section{Model ARIMA}

Model ARIMA merupakan salah satu pemodelan deret berkala yang yang mana merupakan pemodelan deret waktu stasioner. Stasioneritas berarti tidak terdapat 
pertumbuhan atau penurunan data untuk periode waktu tertentu. Kestasioneran dapat dilihat dari kestasioneran nilai tengah atau kestasioneran varian data. Data yang stasioner adalah data dengan nilai tengah atau ragam yang konstan sepanjang waktu pengamatan. Namun pada data deret waktu seringkali menghasilkan data yang tidak stasioner. Data yang tidak stasioner dapat diatasi dengan melakukan transformasi. Salah satu metodenya adalah metode differencing (pembedaan) apabila data tidak stasioner pada nilai tengah. Pembedaan ini dapat dilakukan untuk beberapa periode hingga data bersifat stasioner, yaitu dengan cara mengurangkan satu data dengan data sebelumnya.

Model deret waktu terdiri atas proses white noise, Autoregreesive (AR), model Moving Average (MA) dan model Autoregressive Moving Average (ARMA) dan model Autoregreesive Integrated Moving Average (ARIMA).

Proses white noise memiliki sifat-sifat berikut

1. Deretnya terdiri dari peubah acak yang tidak saling berkorelasi

2. $E\left(x_{t}\right)=0$ untuk setiap $t$

3. $\operatorname{Var}\left(x_{t}\right)=\sigma^{2}$ untuk setiap $t$

4. $\gamma_{k}=\operatorname{Cov}\left(x_{t+k}, x_{t}\right)=0$ untuk $k \neq 0$

Proses white noise dinotasikan sebagai $X_{t} \sim W N\left(0, \sigma^{2}\right)$, dimana proses white noise merupakan proses stasioner.

Model AR merupakan model deret waktu yang dimana nilai pengamatan ke- $t$ dipengaruhi oleh nilai pengamatan sebelumnya. Bentuk umum $\operatorname{AR}(p)$

$$
x_{t}=\mu+\phi_{1} x_{t-1}+\phi_{2} x_{t-2}+\cdots+\phi_{p} x_{t-p}+\varepsilon_{t}
$$

dengan $\mu$ adalah konstanta, $\phi_{t}$ adalah parameter ke- $i$, dan $\varepsilon_{i}$ adalah error saat $t$ dengan $\varepsilon_{t} \sim W N\left(0, \sigma^{2}\right)$.

Model MA menunjukkan pengamatan pada waktu $t, x_{t}$ dipengaruhi oleh galat pada $q$ waktu-waktu $t$ sebelumnya. Bentuk umum model $\operatorname{MA}(q)$

$$
x_{t}=\mu+\varepsilon_{t}-\theta_{1} \varepsilon_{t-1}-\theta_{2} \varepsilon_{t-2}-\cdots-\theta_{q} \varepsilon_{t-q}
$$

dengan $\mu$ adalah konstanta, $\theta_{i}$ adalah parameter ke- $i$, dan $\varepsilon_{t}$ adalah error saat $t$ dengan $\varepsilon_{t} \sim W N\left(0, \sigma^{2}\right)$.

Model $\operatorname{ARMA}(p, q)$ merupakan kombinasi model $\operatorname{AR}(p)$ dan model MA $(q)$. Dimana bentuk umum model $\operatorname{ARMA}(p, q)$

$$
x_{t}=\mu+\phi_{1} x_{t-1}+\phi_{2} x_{t-2}+\cdots+\phi_{p} x_{t-p}+\varepsilon_{t}-\theta_{1} \varepsilon_{t-1}-\theta_{2} \varepsilon_{t-2}-\cdots-\theta_{q} \varepsilon_{t-q}
$$

Model ARIMA merupakan model ARMA setelah dilakukan differencing. Bentuk umum model $\operatorname{ARIMA}(p, d, q)$

$$
(1-B)^{d} x_{t}=\mu+\phi_{1} x_{t-1}+\phi_{2} x_{t-2}+\cdots+\phi_{p} x_{t-p}-\theta_{1} \varepsilon_{t-1}-\theta_{2} \varepsilon_{t-2}-\cdots-\theta_{q} \varepsilon_{t-q}+\varepsilon_{t}
$$

\section{Data dan Metode}

Data yang digunakan dalam penelitian ini adalah data sekunder nilai inflasi di Indonesia yang diterbitkan oleh Bank Indonesia periode bulanan dari 2007 sampai 
2014. Dalam penelitian ini akan dibahas tentang penentuan model nilai inflasi dengan menggunakan model ARIMA.

Langkah-langkah pemodelan ARIMA adalah

(1) Eksplorasi data.

Tahapan ini dilakukan dengan memeriksa plot data dan memeriksa kestasionerannya. Kestasioneran dilakukan secara grafis dan melakukan uji ADF. Bila data tidak bersifat stasioner maka dilakukan pembedaan / differencing.

(2) Pemodelan fungsi mean / rataan.

Untuk mengidentifikasi model rataan, dapat dilihat dari plot ACF dan PACF data nilai inflasi.

(3) Pemodelan inflasi dengan model ARIMA

- Berdasarkan plot ACF dan PACF dapat diidentifikasi model ARIMA yang dapat menggambarkan data. Kemudian dilakukan estimasi model dengan menggunakan model ARIMA dengan kondisional mean yang telah diperoleh sebelumnya.

- Setelah semua model diestimasi, dipilih model terbaik dengan menggunakan kriteria AIC dan SC.

- Langkah selanjutnya adalah melakukan uji diagnostik terhadap model terbaik ARIMA yang telah diperoleh. Uji diagnostik yang digunakan adalah

- Uji Lagrange Multiplier.

Hipotesis uji LM adalah

$H_{0}: \alpha_{1}=\alpha_{2}=\cdots=\alpha_{q}=0$ (tidak terdapat efek ARCH/ragam residual bersifat homoskedastisitas),

$H_{1}$ : paling sedikit ada satu $\alpha_{i}, i=1,2, \cdots, q$ (terdapat efek $\mathrm{ARCH} /$ ragam residual bersifat heteroskedastisitas).

Statistik ujinya yaitu $L M=n R^{2}$, dimana $n$ adalah banyak pengamatan dan $R^{2}$ adalah koefisiendeterminasi dari model regresi residual kuadrat. Statistik uji LM menyebar mengikuti distribusi $\chi^{2}$ dengan $p$ adalah orde dari model $q$ adalah orde dari model ARCH. Hipotesis nol ditolak jika $L M>\chi_{q}^{2}(\alpha)$.

- Uji Korelasi

Untuk melihat korelasi pada residual digunakan uji Q-Ljung Box. Dengan hipotesis

$H_{0}: \rho_{k}=0$ (tidak ada korelasi antar lag),

$H_{1}$ : paling sedikit ada satu $\rho_{k} \neq 0$ dengan $k=1,2, \cdots, K$ (ada korelasi antar lag).

Dan statistik uji yang digunakan adalah

$$
Q_{L B}=n(n+2) \Sigma_{k=1}^{K} \frac{r_{k}^{2}}{n-k^{2}}
$$

dengan $Q_{L B}$ adalah nilai Q-Ljung Box, $n$ adalah banyak pengamatan, $r_{k}^{2}$ adalah koefisien korelasi sisaan pada lag $k$ dengan $k=1,2, \cdots, K$, dan $K$ adalah lag maksimum. Kriteria penolakan hipotesis nol jika $Q_{L B}>x_{k-p-q}^{2}(\alpha)$ atau $p-$ value $<\alpha$. 
- Uji Normalitas

Salah satu uji yang digunakan adalah uji Jarque Bera. Dengan hipotesis pengujian

$H_{0}$ : residual terdistribusi normal

$H_{1}$ : residual tidak terdistribusi normal

dan statistik uji

$$
J B=\frac{n}{6}\left(s^{2}+\frac{(K-3)^{4}}{4}\right)
$$

dengan $n$ adalah ukuran sampel, $K$ adalah nilai kurtosis, dan $S$ adalah nilai skewness. Statistik uji Jarque Bera menyebar chi-square dengan derajat bebas 2 . Hipotesis ditolah jika $J B>$ chi - square.

Suatu model ARIMA dikatakan baik jika melewati semua tahapan uji diagnostik tersebut, maka model terbaik tersebut juga relatif baik untuk memodelkan komponen error data.

(4) Peramalan data masa yang akan datang dengan menggunakan model yang terbaik yang diperoleh.

\section{Model Time Series untuk Nilai Inflasi}

Berikut adalah langkah-langkah pemodelan ARIMA untuk nilai inflasi serta peramalan nilai inflasi selanjutnya

(1) Deskripsi Data.

Data yang digunakan dalam penelitian ini adalah data inflasi bulanan yang diterbitkan oleh Bank Indonesia dari Januari 2007 hingga Desember 2014. Data ini diakses pada tanggal 3 Maret 2015 dengan jumlah pengamatan 96 buah. Tahapan awal identifikasi model rataan adalah dengan melihat plot data stasioner atau tidak. Gambar 1 adalah hasil plot nilai inflasi.

Dari plot di atas menunjukkan bahwa nilai inflasi terlihat memiliki fluktuasi yang beragam dalam kurun waktu tersebut. Dengan adanya fluktuasi yang beragam pada nilai inflasi, dapat disimpulkan data nilai inflasi tidak stasioner. Langkah selanjutnya adalah dilakukan differencing (pembedaan) terhadap data, untuk mengubah data menjadi stasioner. Gambar 2 dan Tabel 1 menunjukkan plot data setelah dilakukan differencing/pembedaan dan hasil uji unit akar.

Dari plot di atas data sudah bapat dikatan stasioner karena sudah tidak terlihat data memiliki fluktuasi. Namun untuk mempertegas dilakukan lah uji unit akar (uji Augmented Dickey-Fuller). Dengan menggunakan uji Augmented Dickey-Fuller diperoleh nilai statistik ADF sebesar -4,937110 dan nilai kritis Dickey-Fuller sebesar -2,892536, dan nilai probabilitas uji 0,0001 yang kurang dari $\alpha=0,05$ yang berarti tolak $H_{0}$, sehingga disimpulkan bahwa data sudah stasioner.

(2) Penentuan Model ARIMA.

Langkah selanjutnya adalah mengidentifikasi model inflasi dengan plot ACF 


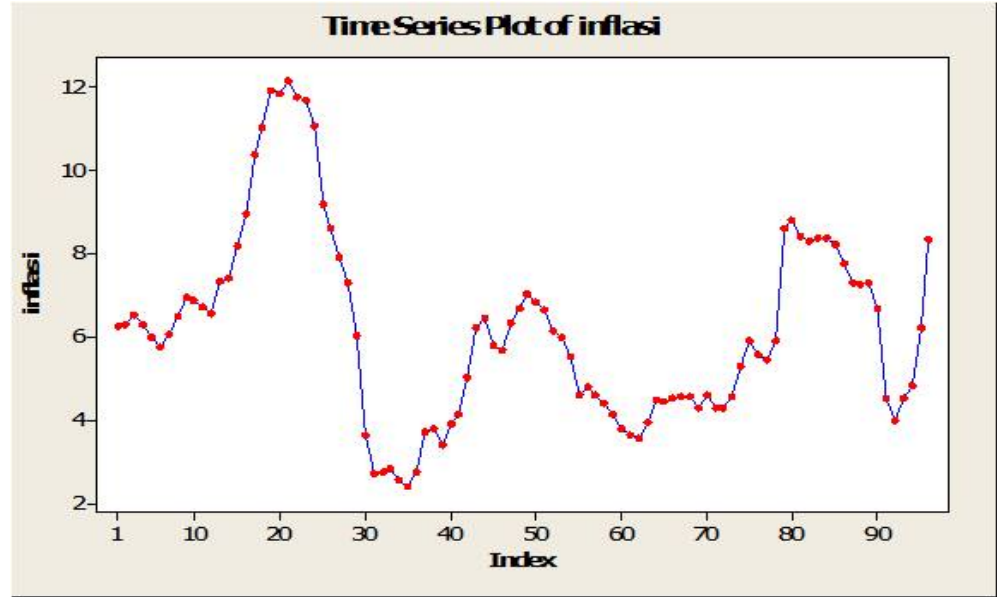

Gambar 1. Plot data inflasi di Indonesia

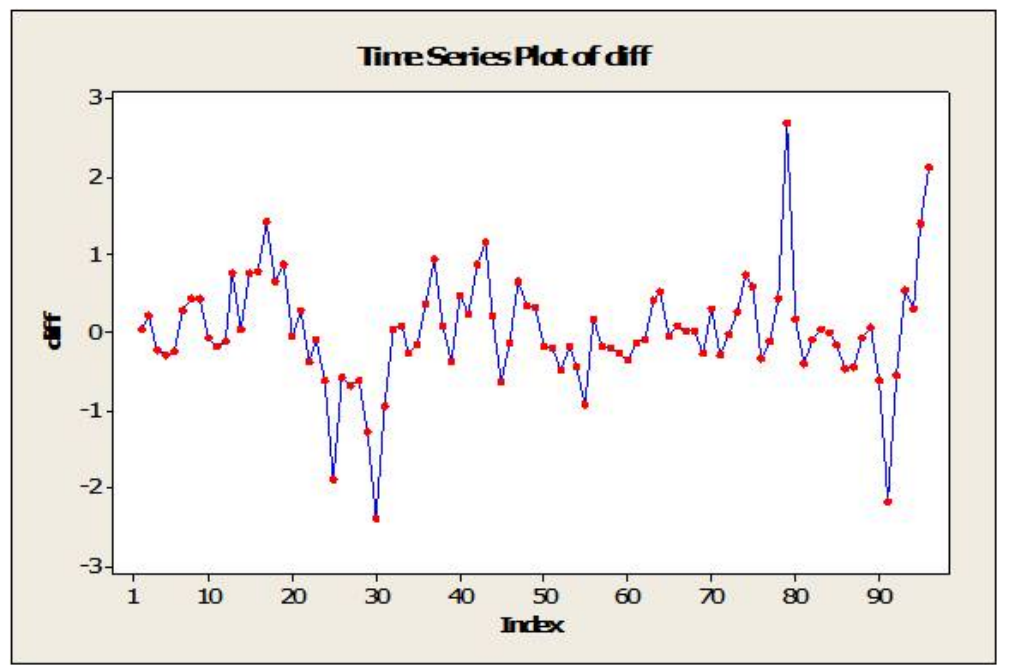

Gambar 2. Plot differencing data nilai inflasi

dan PACF berikut Dari plot ACF dan PACF di atas akan diduga model $\operatorname{ARIMA}(p, d, q)$ dengan orde $p$ dan $q$ dipilih dengan memilih lag yang melewati batas interval, yakni lag 1 dan 12 untuk $p$ dan $q$ tersebut, karena dilakukan differencing/pembedaan satu kali maka $d=1$. Dari hal tersebut terdapat beberapa kemungkinan model untuk data ini, yaitu $\operatorname{ARIMA}(1,1,0), \quad \operatorname{ARIMA}(0,1,1)$ dan $\operatorname{ARIMA}(1,1,1), \quad \operatorname{ARIMA}(12,1,0)$ $\operatorname{ARIMA}(0,1.12), \operatorname{ARIMA}(12,1,12) \operatorname{ARIMA}(1,1,12) \operatorname{ARIMA}(12,1,1)$. 
Tabel 1. Hasil Uji ADF

Null Hypothesis: DIFF1 has a unit root
Exogenous: Constant
Lag Length: O (Automatic - based on SIC, maxlag=11)
\begin{tabular}{lccc}
\hline & t-Statistic & Prob. ${ }^{*}$ \\
\hline \hline Augmented Dickey-Fuller test statistic & -4.937110 & 0.0001 \\
\hline Test critical values: $1 \%$ level & -3.501445 & \\
& $5 \%$ level & -2.892536 & \\
& $10 \%$ level & -2.583371 & \\
\hline \hline
\end{tabular}

*Mackinnon (1996) one-sided p-values.

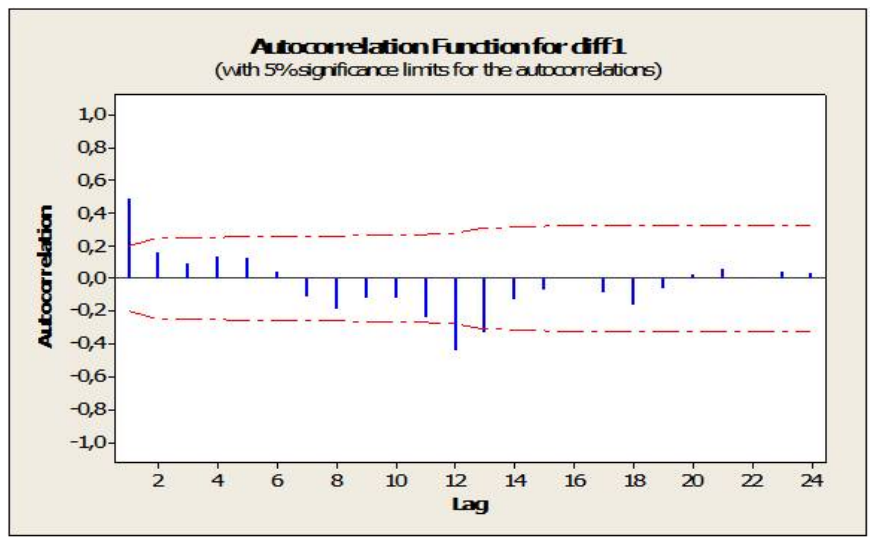

Gambar 3. Plot ACF data nilai inflasi setelah proses differencing

(3) Pemilihan Model Terbaik.

Setelah diperoleh kandidat model nilai inflasi, langkah selanjutnya adalah menentukan model terbaik yang berdasarkan kriteria nilai AIC dan SC yang terkecil. Dari Tabel 2 di atas diperoleh model ARIMA(1,1,12) adalah model

Tabel 2. Rangkaian model ARIMA terbaik

\begin{tabular}{|c|c|c|c|}
\hline Model & AIC & SC & Rangkaian Model \\
\hline ARIMA (1,1,0) & 1,890568 & 1,917624 & 4 \\
ARIMA (0,1,1) & 1,907021 & 1,934804 & 5 \\
ARIMA (12,1,0) & 1,775761 & 1,834046 & 3 \\
ARIMA (0,1,12) & 1,715242 & 1,769007 & 2 \\
ARIMA (1,1,12) & 1,571453 & 1,679678 & 1 \\
\hline
\end{tabular}




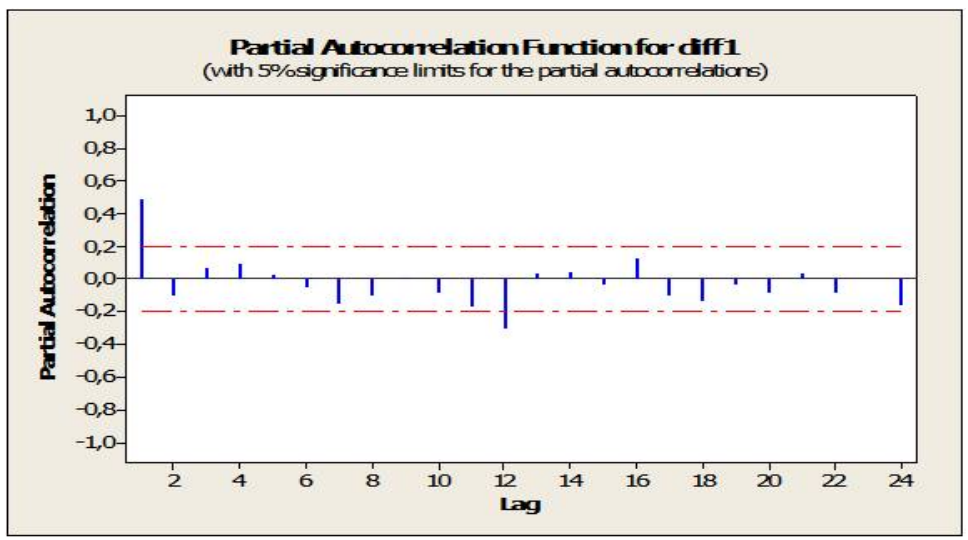

Gambar 4. Plot PACF data nilai inflasi setelah proses differencing

terbaik untuk data nilai inflasi. Persamaan model ARIMA(1,1,12) dituliskan sebagai berikut

$\nabla^{1} x_{t}=0,425764 \nabla^{1} x_{t-1}-0,170124 \varepsilon_{t-4}+0,188143 \varepsilon_{t-10}+0,685578 \varepsilon_{t-12}+\varepsilon_{t}$

(4) Uji Diagnostik Model ARIMA.

Dalam hal ini asumsi yang akan diuji adalah uji kehomogenan (uji Lagrange Multiplier), uji autokorelasi dan uji kenormalan residual.

- Uji Lagrange Multiplier.

Uji ini dilakukan untuk melihat kehomogenan ragam residual. Jika residual memiliki ragam yang konstan, maka model dapat dikatakan baik.

Tabel 3. Hasil Uji Lagrange Multiplier ARIMA $(1,1,12)$

Breusch-Godfrey Serial Correlation LM Test:

\begin{tabular}{llll}
\hline \hline & & & \\
F-statistic & 1.656728 & Prob. F(1,89) & 0.2014 \\
Obs*R-squared & 1.649339 & Prob. Chi-Square(1) & 0.1990 \\
& & & \\
\hline \hline
\end{tabular}

Berdasarkan Tabel 3 dapat dilihat bahwa nilai probabilitas uji > nilai probabilitas chi-square. Artinya ragam residual model $\operatorname{ARIMA}(1,1,12)$ heteroskedastisitas.

- Uji Autokorelasi.

Uji autokorelasi bertujuan untuk melihat ada atau tidaknya autokorelasi antar residual. 
Tabel 4. Output ACF dan PACF

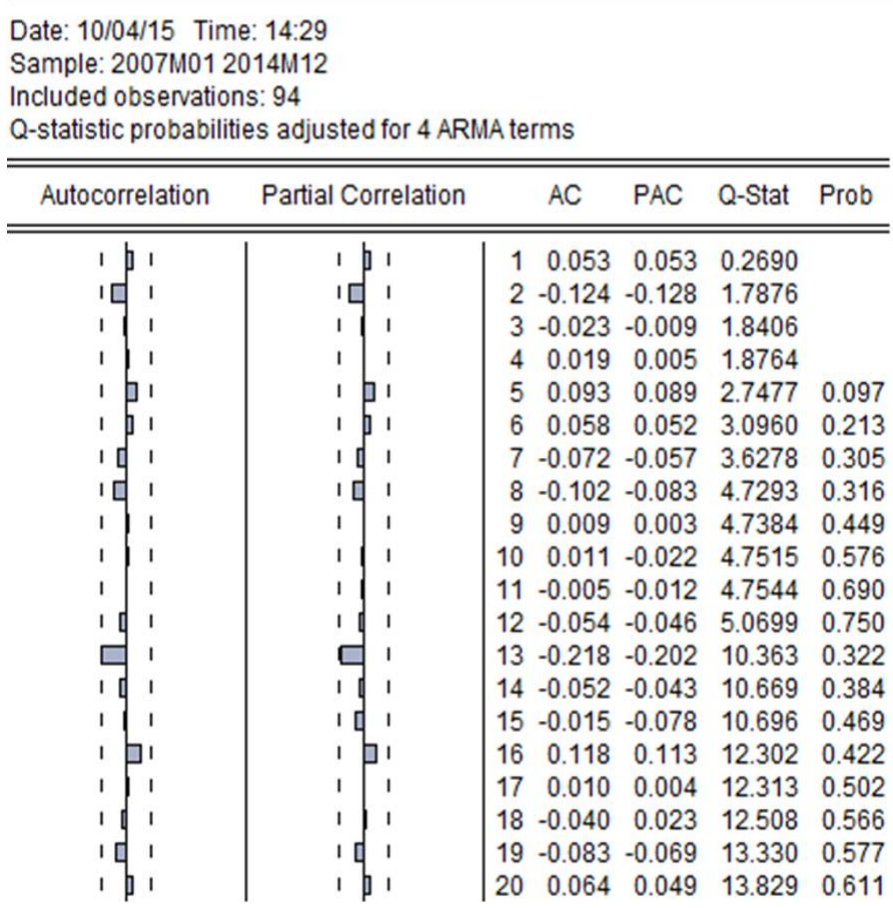

Dari output di atas dapat dilihat bahwa nilai probabilitas lebih dari tingkat signifikan $\alpha=0,05$, artinya residual data tidak mengandung autokorelasi.

- Uji Normalitas.

Uji kenormalan bertujuan untuk melihat kenormalan dari residual. Dari

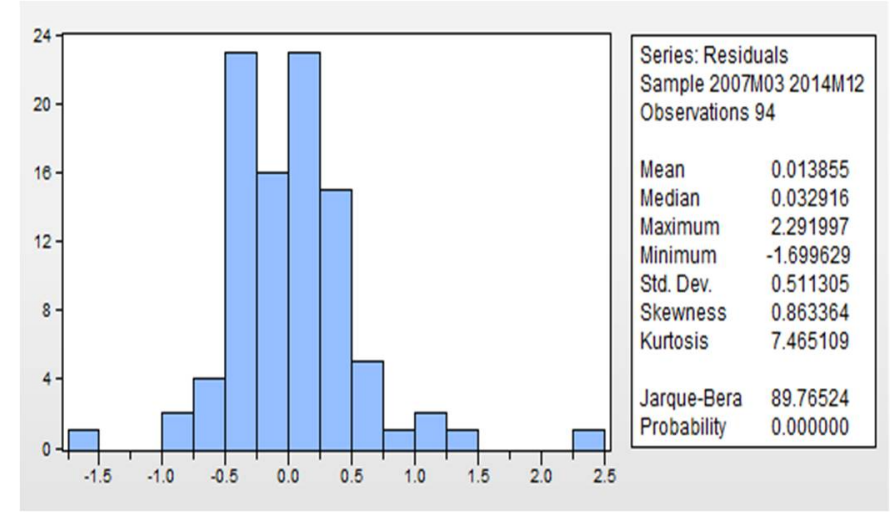

Gambar 5. Histogram kenormalan residual

Gambar 5 dapat dilihat histogram hampir simetris dengan nilai skewness 
(kemencengan) mendekati nol, akan tetapi ada pencilan pada ujung kiri dan kanan yang menyebabkan residual tidak menyebar normal.

(5) Peramalan (Forecasting).

Hasil peramalan nilai inflasi di Indonesia yang diterbitkan oleh Bank Indonesia dari Januari hingga Juni 2015 yaitu

Tabel 5. Perbandingan data aktual dengan hasil peramalan

\begin{tabular}{|c|c|c|c|}
\hline $\mathrm{T}$ & Inflasi & Peramalan & Error $\left(\varepsilon_{t}\right)$ \\
\hline Jan-15 & 6,96 & 6,679 & $-0,281$ \\
Feb-15 & 6,29 & 6,68 & 0,39 \\
Mar-15 & 6,38 & 6,681 & 0,301 \\
Apr-15 & 6,79 & 6,682 & $-0,108$ \\
Mei-15 & 7,15 & 6,683 & $-0,467$ \\
Jun-15 & 7,26 & 6,684 & $-0,576$ \\
\hline
\end{tabular}

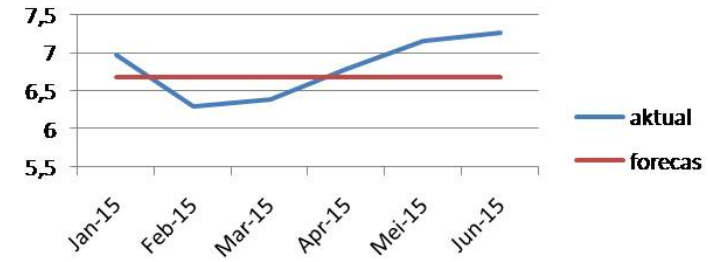

Gambar 6. Grafik perbandingan data aktual dengan hasil peramalan

Dari Gambar 6 terlihat pola data peramalan mendekati pola data aktual. Artinya error yang dihasilkan oleh data hasil peramalan dengan data aktual tidak terlalu besar. Sehingga disimpulkan bahwa model $\operatorname{ARIMA}(1,1,12)$ baik untuk memodelkan nilai inflasi.

\section{Kesimpulan}

Model deret waktu ARIMA dapat digunakan untuk memodelkan nilai inflasi, salah satunya adalah inflasi Bank Indonesia. Pada pembahasan telah diperoleh model yang cocok untuk data nilai inflasi ini adalah model $\operatorname{ARIMA}(1,1,0)$. Dengan bentuk persamaan sebagai berikut

$\nabla^{1} x_{t}=0,425764 \nabla^{1} x_{t-1}-0,170124 \varepsilon_{t-4}+0,188143 \varepsilon_{t-10}+0,685578 \varepsilon_{t-12}+\varepsilon_{t}$

Dari model yang diperoleh dapat dilakukan peramalan dengan error (selisih) data aktual dengan peramalan tidak terlalu besar serta pola plot peramalan yang mengikuti pola plot data aktual. 
74 Lathifah Yulyanisa dkk.

\section{Ucapan Terimakasih}

Penulis mengucapkan terimakasih kepada Ibu Hazmira Yozza, M.Si, Ibu Dr. Ferra Yanuar dan Bapak Yudiantri Asdi, M. Sc yang telah memberikan saran dan kritik dalam penulisan paper ini sehingga penulisan dapat diselesaikan dengan baik.

\section{Daftar Pustaka}

[1] Brocwell, P.J., dan R. A. Davis. 2002. Introduction to Time Series and Forecasting. Springer, New York.

[2] Hamilton, James D. 1994. Time Series Analysis. New Jersey, Princeton University Press.

[3] Montgomery, D.C., C.L. Jennings dan M. Kulahri. 2007. Introduction to Time Series Analysis and Forcasting. Canada, John and Wiley Sons, Inc.

[4] Wei, M.M.S., 1964. Time Series Analysis : Univariate and Multivariate Method. California: Addison-Wesley Publishing Company. 